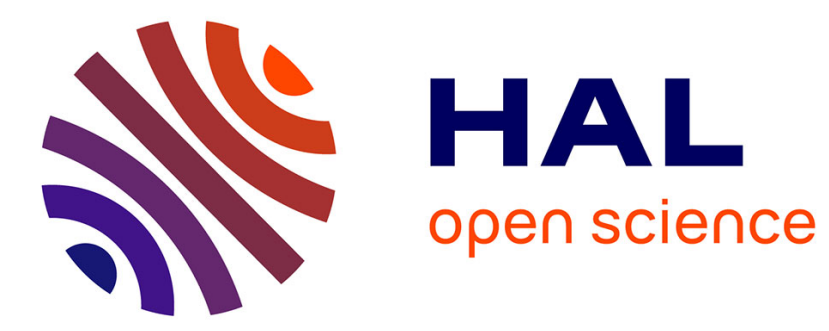

\title{
Utilisation des ultra-sons pour purifier les microsclérotes de Verticillium dahliae Klebahn
}

\author{
Jamel Eddine Henni
}

\section{To cite this version:}

Jamel Eddine Henni. Utilisation des ultra-sons pour purifier les microsclérotes de Verticillium dahliae Klebahn. Agronomie, 1987, 7 (9), pp.743-744. hal-00885049

\section{HAL Id: hal-00885049 \\ https://hal.science/hal-00885049}

Submitted on 1 Jan 1987

HAL is a multi-disciplinary open access archive for the deposit and dissemination of scientific research documents, whether they are published or not. The documents may come from teaching and research institutions in France or abroad, or from public or private research centers.
L'archive ouverte pluridisciplinaire HAL, est destinée au dépôt et à la diffusion de documents scientifiques de niveau recherche, publiés ou non, émanant des établissements d'enseignement et de recherche français ou étrangers, des laboratoires publics ou privés. 


\section{Utilisation des ultra-sons pour purifier les microsclérotes de Verticillium dahliae Klebahn}

Jamel Eddine HENNI

Institut de Biologie, Université d'Oran, Algérie

RÉSUMÉ

L'utilisation des ultra-sons permet de purifier les microsclérotes obtenus à partir de milieu nutritif gélosé.

Mots clés additionnels : Cultures, mycélium, tamis, ultra-sons

Ultrasound has been used to purify microsclerotia obtained from nutrient agar medium.

Additional key words : Cultures, mvcelium. sieve, ultrasound.

La verticilliose est une affection vasculaire qui provoque des dommages graves au cours du développement de nombreuses plantes. Les difficultés de la lutte contre $V$. dahliae résident essentiellement dans la capacité de ce champignon à parasiter de très nombreux hôtes et de produire des organes de conservation, appelés microsclérotes, ces organes de conservation sont capables de survivre dans le sol pendant des périodes qui peuvent atteindre 14 ans (WILHELM, 1955).

Tenant compte du rôle majeur joué par les microsclérotes de $V$. dahliae dans le maintien du potentiel infectieux des sols et dans la multiplication d'attaques, nous avons jugé d'entreprendre des recherches sur leur germination. Pour réaliser ce travail, il nous fallait mettre au point une méthode de séparation de ces microsclérotes à partir de cultures réalisées en milieu nutritif gélosé.

\section{MATÉRIELS ET MÉTHODES}

Pour obtenir des microsclérotes à partir des sols infectés, MENZIES \& CRIEBEL (1967) ont fait appel à des procédés de séparation très simples, par tamisage sur des tamis dont les mailles présentent des ouvertures de dimensions appropriées, s'appuyant sur le fait que les filaments mycéliens libres ne sont pas capables de survivre longtemps dans le sol.

Cette méthode n'est pas utilisable lorsqu'il s'agit d'obtenir des microsclérotes à partir de cultures réalisées en milieu nutritif gélosé. Les filaments mycéliens sont trop abondants. Il nous fallait éliminer ce mycélium, tout en préservant l'intégrité des microsclérotes.

\section{A. Milieu utilisé}

Afin que la formation des microsclérotes soit abondante et accompagnée d'une faible croissance mycélienne, SElvaraJ (1973) recommande l'utilisation de milieux pauvres en source carbonée. Le milieu que nous avons utilisé répond à la composition suivante : Amidon $3 \mathrm{~g}$, Gélose $18 \mathrm{~g}$, Eau $1000 \mathrm{ml}$.

\section{B. Mode de culture}

Le champignon est ensemencé en boîte de Petri puis mis à l'obscurité à $26^{\circ} \mathrm{C}$. Les ensemencements sont 
réalisés par dépôt d'une bouture mycélienne prélevée dans la zone de croissance du thalle. La collecte des microsclérotes est effectuée lorsque les cultures sont âgées de 2 mois. Le vieillissement des cultures s'accompagne d'un dessèchement plus ou moins accusé du substrat et affecte la survie du mycélium sans compromettre celle des microsclérotes (WHALLEY \& TAYLOR, 1976).

\section{Détachement microsclérotes-hyphes}

Un léger grattage superficiel de la culture à l'aide d'un sclapel élimine une grande partie des filaments. Un grattage plus profond, dans la zone mélanisée, permet de recueillir une préparation riche en microsclérotes mais conservant encore des filaments mycéliens. Cette préparation est disposée dans $10 \mathrm{ml}$ d'eau stérile puis partiellement homogénéisée par agitation dans un broyeur mélangeur M.S.E. $\left({ }^{1}\right)$ pendant $3 \mathrm{mn}$. La suspension ainsi obtenue est traitée par des ultrasons (Branson-Sonic-Power-Modèle MS2) pendant

(1) M.S.E. : Measuring and Scientific Equipment.
$30 \mathrm{~s}$ à 3 D.C. Ampères. Ce traitement des hyphes les détache des microsclérotes et permet de les séparer au cours de l'opération suivante.

\section{Séparation des microsclérotes}

Nous avons utilisé 3 tamis superposés de différents maillages d'ouverture de $125 \mu \mathrm{m}, 65 \mu \mathrm{m}$ et $37 \mu \mathrm{m}$, successivement de haut en bas. Après lavage des microsclérotes retenus sur le tamis à $37 \mu \mathrm{m}$, nous les recueillons et procédons à leur purification par décantation dans un tube à essai. Les microsclérotes plus denses se déposent au fond, les fragments mycéliens flottent et sont éliminés.

\section{RÉSULTATS}

Cette technique a permis de recueillir $5.10^{3} /$ microsclérotes $/ \mathrm{ml}$ avec un taux de germination de $95,9 \pm 1,6$, après 24 heures d'incubation à $26^{\circ} \mathrm{C}$.

Recu le 22 janvier 1987. Accepté le 2 juin 1987.

\section{RÉFÉRENCES BIBLIOGRAPHIQUES}

Menzies J. D., Criebel C. E., 1967. Survival and saprophytic growth of Verticillium dahliae in uncropped soil. Phytopathology, 57, 703-709).

Selvaraj J. C., 1973. Effect of carbon, nitrogen ratio on the growth and cultural characteristics of Verticillium spp. Indian Phytopatol., 26 (4), 746-748.
Whalley W. N., Taylor G. S., 1976. Germination of chlamydospores of physiologic races of Fusarium oxyporum f. sp. pisi in soil adjacent to susceptible and resistant pea cultivars. Trans. Br. myc. Soc., 66 (1), 7-13.

Wilhelm S., 1955. Longevity of the Verticillium wilt fungus in the laboratory and field. Phytopathology, 45, 180-181. 